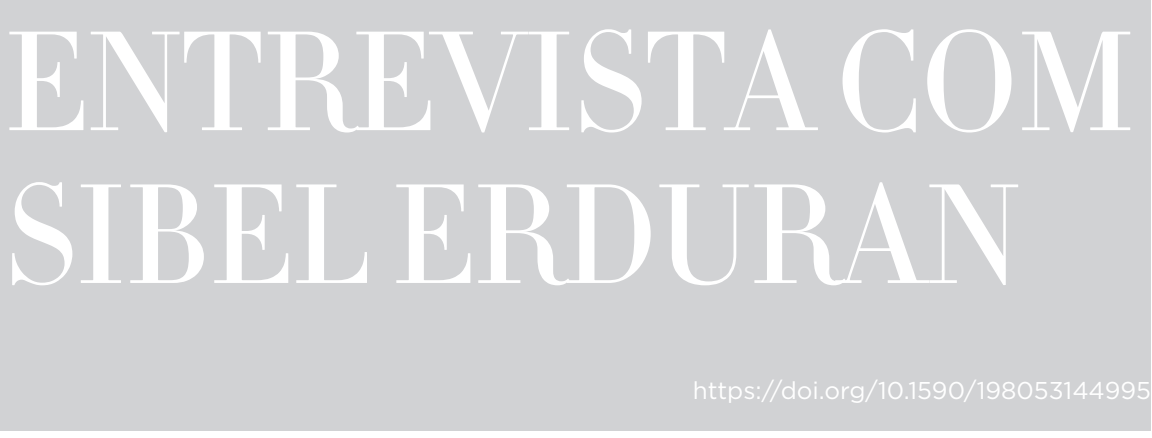

\title{
PERSPECTIVAS DA PESQUISA EM ENSINO DE CIÊNCIAS: ENTREVISTA COM SIBEL ERDURAN
}

\author{
RENATA DE PAULA OROFINO \\ DANIELA LOPES SCARPA"
}

\section{RESUMO}

A pesquisadora Sibel Erduran nos concedeu uma breve entrevista e expôs suas ideias sobre a pesquisa em Ensino de Ciências. Conversamos sobre as opções teóricas utilizadas no desenvolvimento do modelo de Natureza da Ciência construído pela pesquisadora em seus trabalhos recentes; a contribuição de diferentes tópicos de pesquisa para a produção de conhecimento sobre Ensino de Ciências; e sobre suas impressões quanto às diferentes metodologias de pesquisa utilizadas no Ensino de Ciências. Abordamos as opiniões da pesquisadora sobre as consequências da manutenção das estratégias tradicionais de Ensino de Ciências e quais poderiam ser as atitudes adotadas por pesquisadores e professores para diminuir a lacuna entre a pesquisa em Ensino de Ciências e a prática educacional.

\section{ENSINO DE CIÊNCIAS • FILOSOFIA • CIÊNCIA • PESQUISA EDUCACIONAL}

\section{PERSPECTIVES OF SCIENCE EDUCATION RESEARCH: INTERVIEW WITH SIBEL ERDURAN}

\section{ABSTRACT}

The researcher Sibel Erduran gave us a brief interview and shared her ideas about Science Education research. We talked about the theoretical choices she made, to develop the model of the Nature of Science that she used in her recent studies; the contribution of several research topics to the production of knowledge about Science Education; and, her thoughts concerning the different research methodologies used in Science Education. We discussed the researcher's opinions about the consequences of maintaining traditional strategies in Science Education, and what attitudes could be adopted by researchers and teachers to reduce the gap between research and practice in Science Education. 
La chercheure en Enseignement des Sciences, Sibel Erduran, nous a accordé un entretien durant lequel elle a exposé ses idées sur la recherche en enseignement des Sciences. Nous avons discuté des options théoriques ayant trait au développement du modèle des Sciences de la Nature construit par la chercheure dans ses travaux les plus récents. Elle nous a aussi donné son opinion sur différentes méthodologies de recherche utilisées en Enseignement de Sciences aujourd'hui, ainsi que sur les conséquences du maintien des stratégies traditionnelles utilisées dans le cadre de cet enseignement. Finalement, elle a suggéré ce que chercheurs et enseignants pourraient faire pour rapprocher la recherche en Enseignement des Sciences des pratiques éducatives.

ENSEIGNEMENT DES SCIENCES • PHILOSOPHIE • SCIENCE • RECHERCHE EN ÉDUCATION

La investigadora Sibel Erduran, nos concedió una breve entrevista y expuso sus ideas sobre la investigación en Enseñanza de Ciencias. Conversamos sobre las opciones teóricas utilizadas en el desarrollo del modelo de Naturaleza de la Ciencia construido por la investigadora en sus trabajos más recientes; la contribución de diferentes tópicos de investigación para la producción de conocimiento sobre la Enseñanza de Ciencias; $y$ sobre sus impresiones sobre las diferentes metodologías de investigación utilizadas en esta área. Abordamos las opiniones de la investigadora sobre las consecuencias del mantenimiento de las estrategias tradicionales de la Enseñanza de Ciencias y cuales podrían ser las actitudes adoptadas por investigadores y profesores para disminuir la brecha entre la investigación en la Enseñanza de Ciencias y la práctica educativa. 


\section{APRESENTAÇÃO}

Sibel Erduran teve formação inicial em Química e atua na pesquisa em Ensino de Ciências desde o final da década de 1990. Atualmente, é professora e pesquisadora na Universidade de Oxford, Inglaterra, além de ser colaboradora na Universidade de Limerick, Irlanda, e na Universidade Nacional Normal de Taiwan, Taiwan. Pesquisadora com vasta experiência na área, já atuou na Suécia, na Turquia e no Reino Unido, além de participar como editora de proeminentes revistas científicas da área. Possui, aproximadamente, 150 artigos publicados em revistas, além de mais de 130 apresentações em eventos científicos da área. Realiza pesquisa com temas diversos, especialmente relacionados à Natureza da Ciência $(\mathrm{NdC})$, às práticas epistêmicas da Ciência e à argumentação no Ensino de Ciências.

Tivemos a oportunidade de entrevistar a pesquisadora durante uma visita à Universidade de Limerick no mês de dezembro do ano de 2014. A entrevista foi gravada, transcrita e traduzida. Reorganizamos as perguntas para destacar os tópicos mais relevantes discutidos e editamos o texto das perguntas apenas para torná-las mais claras, uma vez que a entrevistadora não é nativa na língua inglesa. A conversa cobriu tópicos de interesse geral a pesquisadores em Ensino de Ciências: NdC como tema relevante na pesquisa em Ensino de Ciências; tendências e metodologias de pesquisa em Ensino de Ciências; relações entre teoria e prática na pesquisa e no ensino; e impacto do Ensino de Ciências no 
cotidiano. Apresentamos uma discussão inicial sobre os tópicos tratados na entrevista, seguida da entrevista.

NdC é um tema de pesquisa em Ensino de Ciências dedicado a investigar os elementos envolvidos na construção do conhecimento científico. Diferentes pesquisadores da área ressaltam as muitas facetas da construção do conhecimento científico com diferentes graus de importância e relevância para o Ensino de Ciências. Alguns autores sugerem que há uma visão consensual de $\mathrm{NdC}$, ou seja, alguns dos elementos discutidos na literatura são recorrentes e têm sua pertinência para a educação científica reconhecida (discussão presente em MATTHEWS, 2012). Os elementos considerados consensuais (LEDERMAN, 1992) são: a natureza empírica do conhecimento científico; a distinção entre teorias científicas e leis; a natureza criativa e imaginativa do conhecimento científico; a natureza orientada pela teoria da produção do conhecimento científico; a inserção social e cultural do conhecimento científico; o mito do método científico; e a natureza tentativa do conhecimento científico. Como apontado por Azevedo e Scarpa (2017), diversos autores se opõem à visão consensual, argumentando contra a ideia de finitude embutida na proposição de uma lista e indicando tanto a ausência de aspectos relevantes (como o papel do feminismo ou as especificidades de áreas), quanto a falta de profundidade sobre os processos de produção do conhecimento científico.

Erduran e Dagher (2014) sugerem uma abordagem mais ampla de NdC (Figura 1), baseada em uma visão cognitivo-epistêmica de Ciência como parte de um sistema social-institucional (IRZIK; NOLA, 2011). O esquema fia-se no conceito de Semelhança de Família (ideia de que as ciências podem ser agrupadas em famílias pelas semelhanças de suas características e que esses agrupamentos podem ter sobreposições), baseado no trabalho de Wittgenstein (ERDURAN; DAGHER, 2014). Cada prática científica (p.ex. formular hipóteses, desenvolver experimentos, realizar observações) estaria imersa em valores sociais (p.ex. honestidade) e sujeita à certificação (p.ex. na publicação científica), à organização institucional e aos sistemas de financiamento (p.ex. infraestrutura institucional e auxílio financeiro à pesquisa), e também às estruturas de poder financeiro (p.ex. programas nacionais ou estaduais de incentivo à pesquisa).

A visão ampliada de NdC como sendo o conjunto de ações, valores e certificações no processo de construção do conhecimento científico aumenta as possibilidades de conexão entre os diferentes trabalhos de pesquisa em Ensino de Ciências. Diferentes autores defendem o ensino por investigação (SCHWARTZ; LEDERMAN; CRAWFORD, 2004) e o ensino por argumentação (KUTLUCA; AYDIN, 2017) como abordagens privilegiadas para ensinar aspectos de NdC e o tema NdC pode ser identificado nos textos curriculares de diferentes países (NGSS LEAD STATES, 2013; BRASIL, 2017). 


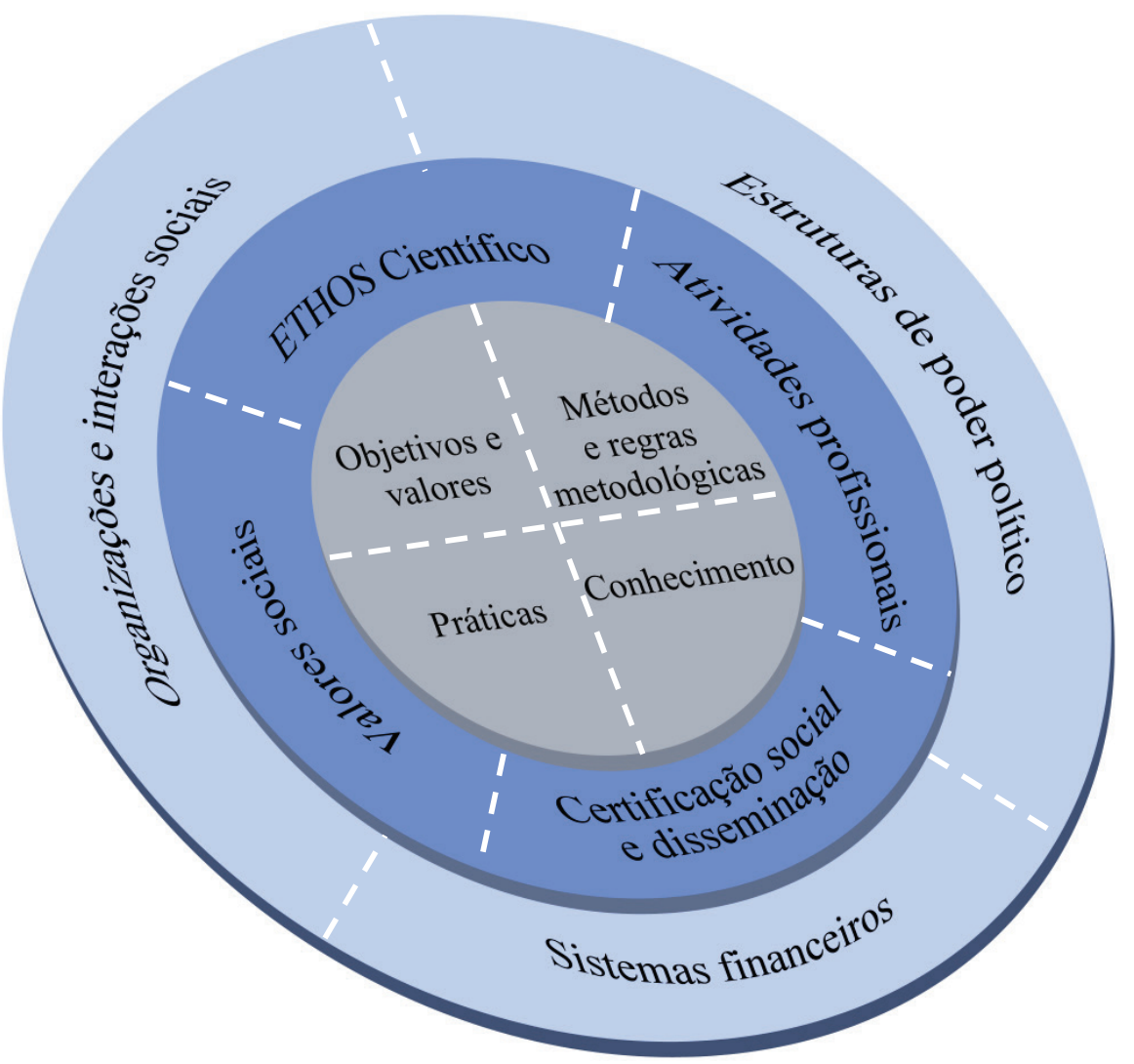

Fonte: Adaptada de Erduran e Dagher (2014).

Os discos de semelhança de família criados por Erduran e Dagher retratam a Ciência como um sistema cognitivo-epistêmico e socioinstitucional. Os discos representados têm centro comum, mas giram uns sobre os outros e as linhas pontilhadas indicariam a permeabilidade entre os temas, representando a complexidade das interações entre as facetas da construção do conhecimento científico.

Temas como NdC são relevantes tanto para a pesquisa quanto para o Ensino de Ciências. Tendências de pesquisa nos ajudam a entender e parametrizar o percurso dos cientistas nas diferentes áreas do conhecimento, além de dar diretrizes aos novos pesquisadores da área sobre quais caminhos de pesquisa seguir (LIN; LIN; TSAI, 2014). Um trio de artigos indica tendências de pesquisa na área de Ensino de Ciências (TSAI; WEN, 2005; LEE; WU; TSAI, 2009; LIN; LIN; TSAI, 2014). 
Os autores do grupo investigaram publicações feitas em três revistas ao longo de 15 anos. Além de concluírem que os trabalhos empíricos são maioria entre os tipos de artigos publicados (quando comparados a trabalhos teóricos ou de opinião), os autores apresentam os tópicos de pesquisa mais frequentes entre 1998 e 2012 (Tabela 1). Dentre os tópicos contabilizados, dois deles tratam de aprendizagem, um mais voltado para os conceitos científicos e outro mais voltado para os contextos de sala de aula. Os autores citam uma diminuição no número de publicações sobre Mudança Conceitual - alocado em Aprendizagem (conceitos) - e um aumento no número de pesquisas sobre Ensino por Investigação, tema alocado em Aprendizagem (contextos). Aprendizagem (contextos) se manteve como o tópico mais publicado desde 2003.

\section{TABELA 1}

INDICA OS TÓPICOS DE TRABALHO MAIS REALIZADOS EM TRÊS GRANDES REVISTAS DA ÁREA DE ENSINO DE CIÊNCIAS

\begin{tabular}{l|c|c|c}
\hline TÓPICO & 1998 A 2002 & 2003 A 2007 & 2008 A 2012 \\
\hline Formação de professores & $7,0 \%$ & $9,0 \%$ & $6,3 \%$ \\
\hline Ensino & $6,9 \%$ & $13,9 \%$ & $18,6 \%$ \\
\hline Aprendizagem (conceitos) & $24,7 \%$ & $15,3 \%$ & $15,2 \%$ \\
\hline Aprendizagem (contextos) & $17,9 \%$ & $23,5 \%$ & $36,9 \%$ \\
\hline Políticas Públicas, currículo e avaliação & $13,6 \%$ & $12,7 \%$ & $4,9 \%$ \\
\hline Cultural, social, questões de gênero & $14,3 \%$ & $6,8 \%$ & $4,8 \%$ \\
\hline História, filosofia e epistemologia da Ciência & $8,5 \%$ & $8,2 \%$ & $6,3 \%$ \\
\hline Tecnologias da educação & $3,4 \%$ & $5,4 \%$ & $3,8 \%$ \\
\hline Educação não formal & $3,7 \%$ & $5,3 \%$ & $3,4 \%$ \\
\hline
\end{tabular}

Fonte: Adaptada de Lin, Lin e Tsai (2014).

Alguns temas de pesquisas, por mais interessantes que sejam, já foram amplamente desenvolvidos e a contribuição seria maior se usássemos tais conhecimentos como ponto de partida para novas perguntas de pesquisa. Uma vez estabelecida a necessidade de considerar os conhecimentos prévios dos alunos e alunas (p.ex. BASER, 2006), como as estratégias de levantamento de concepções prévias têm sido implantadas no ensino por investigação? Uma vez que os alunos e alunas apresentam perfis conceituais sobre os diferentes temas como resultado da construção do significado nos diferentes contextos em que determinado conceito é utilizado (MORTIMER; EL-HANI, 2014), quais as formas de ajudar os alunos e alunas a utilizarem os conceitos esperados nos contextos científicos? Uma vez que sabemos que o tipo de perguntas realizadas em sala de aula têm diferentes objetivos (ELIASSON; KARLSSON; SØRENSEN, 2017), quais os objetivos voltados para cada estratégia instrucional ou grupo de alunos e alunas? Já que as interações discursivas em sala de aula podem favorecer ou dificultar o aprendizado em Ciências 
(p.ex. SILVA; MORTIMER, 2013), quais os padrões de interação que maximizam a construção de conhecimentos pelos alunos?

Discussões sobre temas, tópicos e tipos de trabalhos realizados na área são relevantes, não apenas para entendermos a visão que os pesquisadores da área têm sobre como se constrói o conhecimento na área, mas também para conseguirmos reunir informações sobre pesquisas com um mesmo perfil ou ainda construir conclusões mais abrangentes na escala global. Este é o caso de uma metanálise realizada em 2014 (FREEMAN et al., 2014), que indica que os alunos e alunas apresentam melhor desempenho e menores taxas de reprovação em sequências didáticas em que há algum tipo de estratégia ativa de aprendizagem. Para chegarem a tais conclusões, os autores classificaram 225 trabalhos, reunindo pesquisas de diferentes lugares do mundo e consolidando conclusões feitas pontualmente para demais contextos.

Todos os trabalhos foram retirados de uma busca em 55 periódicos entre 1998 e 2010, usando, como um dos critérios de seleção, trabalhos com desenho experimental controle e tratamento. O grande número de trabalhos com esse tipo de metodologia ajuda a justificar a importância de trabalhos experimentais na pesquisa em educação com foco no teste de estratégias didáticas diferentes de aulas expositivo-dialogadas e mostram também que é possível realizar pesquisas com tal método na educação. Algumas das perguntas científicas sobre qualidade de ensino e aprendizagem precisam de métodos científicos capazes de responder tais perguntas, ou seja, em alguns casos, a pesquisa precisa de parâmetros quantitativos de coleta e análise de dados para que possamos construir conclusões.

Mesmo quando trabalhamos com metodologias experimentais, é interessante trazer à tona a iminência do efeito Hawthorne nas pesquisas em educação (COOK, 1962) para balizar as conclusões construídas. O efeito Hawthorne, fenômeno caracterizado pela consciência que os sujeitos de pesquisa tomam de que são especiais em virtude do tratamento recebido durante a pesquisa, dificultaria correlações entre "variáveis preditoras" e "variáveis resposta”, e nos ajudaria a entender por que grupos experimentais e controles tiveram resultados semelhantes. Por causa do efeito Hawthorne, os pré-testes são recomendados, para que seja possível identificar o ganho tanto do grupo experimental quanto do grupo controle, mas, mesmo assim, efeitos positivos gerados no grupo experimental podem ser resultado de outras variáveis preditoras, diferentes das planejadas no experimento.

Os cuidados éticos e morais que protegem alunos e professores servem para garantir que nenhum dano moral seja infligido aos participantes das pesquisas. Os comitês de ética no Brasil têm se fortalecido e nos ajudam a garantir a segurança dos sujeitos de pesquisa para que possamos construir conclusões generalizáveis sobre o Ensino de Ciências 
nos diferentes contextos brasileiros. Freeman et al. (2014) sugerem uma solução interessante, de que pesquisas em Ensino de Ciências poderiam adotar estratégias semelhantes às das pesquisas de Saúde Pública e Medicina, nas quais os pesquisadores, quando percebem o benefício do tratamento experimental durante a execução do experimento, suspendem o tratamento controle e passam a administrar o tratamento experimental para todos os sujeitos de pesquisa.

Escolhas metodológicas como a indicada anteriormente são, para além das questões éticas, formas de aproximar a pesquisa em Ensino de Ciências da prática pedagógica. Não é apenas na Educação que as questões abordadas nas pesquisas se distanciam do cotidiano de quem exerce a prática. Remédios testados em pesquisas nem sempre chegam aos médicos, inovações de engenharia nem sempre chegam à construção civil, soluções potenciais para questões ambientais nem sempre são implementadas nos contextos político e social. Na educação, uma das lacunas existentes é entre a atuação dos professores e a sugestão de atuação dada pelas pesquisas. Conclusões, indicações ou sugestões de ação presentes nas pesquisas não chegam aos professores, são desproporcionais para realidades específicas ou ainda são impossíveis de serem realizadas dadas as restrições estruturais e financeiras das diferentes escolas e regiões. Além disso, pesquisas em contextos muito diferentes dos que o professor trabalha podem se mostrar menos úteis para a prática.

Pelo ponto de vista da prática pedagógica, nem sempre as pesquisas realizadas tangem os assuntos mais caros aos professores, ou seja, os pesquisadores não estariam sendo capazes de entender os desafios enfrentados pelos professores. Outro problema encontrado envolve uma visão do professor em sala de aula como um repetidor, executor ou técnico que aplica cegamente as sequências didáticas e formas de ação sugeridas pelas pesquisas. Pesquisas realizadas sem considerar o conhecimento acumulado pelos professores ao longo de suas práticas pontuais podem não apresentar ressonância na realidade.

Não podemos continuar restringindo a realização de pesquisas científicas em Ensino de Ciências aos pesquisadores da universidade sem incluir nem dar suporte aos professores em sala de aula. A diminuição da lacuna entre a pesquisa e a prática provavelmente não ocorre apenas pela escolha de temas relevantes das pesquisas realizadas, mas pela coordenação das pesquisas em parcerias com os professores atuantes na educação básica, superior e na formação inicial e continuada dos profissionais relacionados à escola. A criação de centros integrados de pesquisa podem sedimentar e fortalecer o relacionamento entre pesquisadores e professores, de forma a empoderar os professores e torná-los produtores do conhecimento sobre ensino. A construção de comunidades de prática, o incentivo financeiro, a inclusão de tempo previsto para a realização de pesquisa nos contratos dos profissionais da educação e a parceria com centros de pesquisa podem ser 
ferramentas fundamentais para a construção de uma ponte eficaz entre pesquisa e prática na área de Ensino de Ciências.

Uma iniciativa brasileira nesse sentido é o Programa Institucional de Bolsa de Iniciação à Docência (Pibid) da Coordenação de Aperfeiçoamento de Pessoal de Nível Superior (Capes). O programa é voltado tanto para a formação inicial de professores quanto para a valorização dos conhecimentos dos professores já atuantes no ensino básico e é realizado com apoio de professores universitários de cursos de licenciatura. O programa não só permite que o professor em formação inicial tenha contato com o contexto educacional, mas também permite que os estágios em sala de aula ultrapassem a observação passiva das estratégias didáticas do professor em exercício e se tornem espaços colaborativos e criativos para se produzir conhecimento sobre e na sala de aula. Para estimular o engajamento dos diferentes atores (i.e. alunos da licenciatura, professores da educação básica e professores universitários), a Capes oferece editais e financiamento para os participantes, permitindo um maior entrosamento dos diferentes profissionais envolvidos.

Um dos objetivos de diminuir a lacuna entre pesquisa e prática é ajudar a solucionar os problemas de alfabetização existentes no país. No contexto brasileiro, a maior parte da população entre 15 e 40 anos, tendo quatro ou mais anos de estudo, residentes em nove das regiões metropolitanas do país, apresentam nível intermediário de letramento científico, sendo que o mais comum é ter conhecimento científico rudimentar, em que o indivíduo reconhece termos científicos, mas não consegue interpretar situações ou resolver problemas de natureza científica (SERRÃO et al., 2016). Explicações de outros campos do conhecimento são utilizadas para fenômenos amplamente discutidos e esclarecidos pela Ciência e em diversas situações, as soluções encontradas para os problemas são temporárias ou ainda podem acarretar acidentes ou problemas de saúde. Em uma sociedade altamente dependente da Ciência e da tecnologia, o Ensino de Ciências e a alfabetização científica são cruciais para que os cidadãos entendam o mundo e possam se posicionar diante das diferentes questões impostas no dia a dia pelas ciências. As contribuições da Ciência para a sociedade são incontáveis e ter acesso a esse conhecimento é um direito dos cidadãos.

A entrevista com a proeminente pesquisadora nos ajuda a reafirmar nossas metas como pesquisadores e também como professores de Ciências no ensino básico e superior, além de nos ajudar a reforçar conviç̧ões e conhecimentos já estabelecidos sobre a importância do Ensino de Ciências na sociedade atual. 


\section{ENTREVISTA}

Renata de P. Orofino (RPO) e Daniela L. Scarpa (DLS): Poderíamos

dizer que seus interesses de pesquisa estão mudando para questões relacionadas à $\mathrm{NdC}$ ?

S. Erduran: Certo, primeiramente não acho que meus interesses de pesquisas mudaram, mesmo que fundamentalmente possa parecer, pois como você sabe, tenho realizado pesquisas sobre argumentação nos últimos 20 anos e eu entendo que a argumentação é um dos aspectos da NdC. Então, mesmo que não tenha me referido, por exemplo, à NdC no contexto da argumentação, a argumentação é um aspecto da NdC. Esse é um ponto. O outro ponto é que parte da minha pesquisa é sobre filosofia da Química. Assim, estou interessada na natureza da Química, natureza do conhecimento e do raciocínio em Química, também aspectos da NdC em um contexto particular de um dos domínios das Ciências. Portanto, as duas linhas-chave de pesquisa que eu tenho conduzido nos últimos anos, argumentação e filosofia da Química, são ambas exemplos de diferentes aspectos da NdC. Um deles é sobre um tipo de raciocínio, ou seja, um aspecto epistêmico da construção do conhecimento, no contexto da argumentação. O outro é sobre um domínio particular de Ciência, a Química. Porém, você está certa se pensarmos que recentemente tenho me interessado pelos assuntos mais gerais sobre $\mathrm{NdC}$ e explicitamente tenho me referido à $\mathrm{NdC}$ em meus trabalhos.

RPO e DLS: Aparentemente, há diferentes pontos de vista sobre como a NdC deveria ser implementada nos contextos educacionais. Como nos beneficiamos dos trabalhos já realizados pelos pesquisadores que apresentam diferentes visões e propostas sobre $\mathrm{NdC}$ ?

S. Erduran: Essa área de pesquisa não é nova. Muitos pesquisadores já deram contribuições sobre o assunto nas últimas décadas. Acho que a contribuição significativa dos trabalhos já existentes é que eles evidenciaram a importância de promover propostas de ensino de $\mathrm{NdC}$ na Ciência escolar. Eu vejo que a maior contribuição das pesquisas em NdC foi a de garantir a validade do tema no currículo escolar de Ciências. Entendo que contribuíram para esse importante objetivo no Ensino de Ciências.

RPO e DLS: Quais aspectos da proposta teórica que você publicou recentemente com Dagher são consonantes com as ideias dos pesquisadores ícones da área, como Lederman e Mathews? E em quais aspectos você discordaria das opiniões de tais pesquisadores? 
S. Erduran: Sobre as semelhanças e diferenças principais entre as linhas de pesquisa citadas e o nosso trabalho, especialmente no nosso livro recente, ${ }^{1}$ são que a visão consensual tem uma série de afirmações declarativas sobre o que constitui a Ciência. Afirmações como "o conhecimento científico é tentativo”, “a Ciência é cultural e socialmente influenciada”. Obviamente, não poderia discordar de tais afirmações, quero dizer, no nível da lista declarativa eu não necessariamente discordaria delas, porque são afirmações consensuais na comunidade.

Acredito que minha discordância quanto a essa visão não seja tanto pelo conteúdo, mas em relação aos parâmetros que essas afirmações proporcionam para que os profissionais que elaboram currículos escolares ou os professores entendam o que é NdC. Então, qual o potencial dessas afirmações em ajudar a construir uma sequência didática, por exemplo? Em posse de tais afirmações, como proceder (como professores ou desenvolvedores de currículo)? Essa é uma das minhas questões na nossa proposta teórica.

Outra questão é que alguns dos princípios são muito particulares. Por exemplo, o princípio que diz que teorias são diferentes de leis. Eu me pergunto: por que considerar somente a relação entre essas formas de conhecimento científico, “teorias e leis”, se há outras formas, como os modelos, por exemplo. Por que valorizar um único tipo de relação? Me parece bastante arbitrário. Não apenas arbitrário, mas nós não estamos olhando para o ponto mais abrangente, o conhecimento científico.

Uma terceira questão que tenho com os princípios, de forma mais geral, é que são uma lista de afirmações desconectadas. Como tais afirmações se somam à Ciência e à NdC de forma mais geral? Então, de certo modo, é uma lista fragmentada de afirmações que não necessariamente adicionam ao todo, não resumem a história a ser contada sobre a Ciência. Sendo assim, em parte, o que fizemos foi tentar encontrar categorias mais abrangentes para ilustrar como os diferentes aspectos da Ciência contribuem para a NdC. Cada um dos princípios seria um exemplo dessas categorias, mas em nosso esquema seria possível resumir a história do que é NdC.

Primeiramente, quais seriam os objetivos e valores da Ciência? Qual dos dois ditaria por que cientistas fazem Ciência e o que fazem? E veja, objetivos e valores não são elementos declarados na visão consensual. Como os cientistas fazem Ciência? Quais são as práticas aplicadas por eles? Quais são os métodos? Quais as consequências obtidas como resultado das práticas e métodos utilizados? Qual é o conhecimento científico construído e quais são as questões sociais, políticas, culturais e financeiras mais amplas envolvidas? Qual é o Ethos da Ciência? Quais são os valores sociais embutidos nas práticas científicas? Então, quando você começa a falar de Ciência dessa forma, você constrói uma figura 
mais holística, o que ajuda a entender por que os cientistas fazem o que fazem, onde e como o fazem. Isso cria uma história coerente que é inclusiva em diferentes aspectos, muito diferente de listar afirmações que não representam imediatamente o todo.

RPO e DLS: Quando eu comecei a participar de um grupo de pesquisa em Ensino de Ciências (por volta de 2008), tinha vontade de trabalhar com mudança conceitual sobre um conceito específico. Então, me deparei com afirmações como: "Não há mais o que pesquisar", "está esgotado". Sabemos ao menos que não é mais um tópico em alta. Você acha que realmente superamos e esgotamos a pesquisa em mudança conceitual? $\bigcirc$ que teríamos a buscar sobre mudança conceitual?

S. Erduran: Como editora, eu ainda recebo artigos sobre o tema. Digo ainda porque mudança conceitual não é um tópico dominante na nossa área de pesquisa atualmente. Mas ainda recebo artigos sobre, por exemplo, concepção de alunos do país X sobre eletricidade, sendo que já sabemos as concepções de alunos sobre eletricidade no país Y. O fato de você ter conduzido uma pesquisa em outro contexto não necessariamente adiciona valor ao artigo, ao menos que você consiga mostrar a principal contribuição do contexto particular analisado. O que eu vejo muito são pessoas repetindo o que já está feito. Então, nesse sentido, não há uma contribuição se você não apresenta algo para aprofundar o conhecimento em um assunto (campo).

Há diferentes linhas de pesquisa em Ensino de Ciências, muitos trabalhos já foram feitos, trabalhos sobre concepções, concepções alternativas, mudança conceitual, principalmente nos anos de 1980 e 1990, da qual acumulamos muita informação nessa área. Então, a menos que uma nova visão possa ser incluída (demonstrada), essa não é uma área profícua a se fazer pesquisa. A ideia de realizar uma pesquisa em um novo contexto não a torna interessante, a menos que você consiga argumentar que tal pesquisa nos ajuda a ter novas perspectivas, certo? Então, eu consigo entender por que as pessoas podem dizer que é um assunto ultrapassado. Já tomou seu rumo, muitas pessoas já realizaram pesquisa no assunto. Dessa maneira, se está propondo realizar uma pesquisa nessa área hoje, você precisa mostrar qual será sua contribuição, senão, será apenas uma repetição do que já está posto.

RPO e DLS: Uma das razões para alguns pesquisadores não realizarem experimentos nas pesquisas em Ensino de Ciências é a concepção de que seria injusto não proporcionar a todos os alunos uma estratégia didática considerada melhor que outra.

Na sua opinião, esse argumento é apoiado em evidência? Alguns poderiam pensar que se essa forma de ensinar é melhor, 
um experimento controlado nos daria a resposta exata que esperamos se de fato é melhor ou não. Você concorda com isso, ou melhor, qual sua opinião sobre o assunto? Não apenas se é ético ou não, se há um entrave ético, seriam pesquisas que deveríamos tentar realizar, mesmo havendo uma questão ética? Porque alguns poderiam dizer que é antiético, outros que não é, uma vez que não sabemos qual modo de ensinar é melhor. Então, há um problema ético em realizar esse tipo de pesquisa e seria a única saída para descobrirmos se um determinado modo de ensino é melhor que os outros?

S. Erduran: Esse é um assunto complexo. Claramente, é esperado que haja uma linha de pesquisa que realize testes de intervenções. Para isso, seria necessário um desenho com controle, ou um experimento com intervenções experimental e controle. Penso que se queremos apresentar, gerar evidências sobre o impacto e efetividade de uma estratégia, nós temos que usar esse tipo de metodologia na pesquisa em Ensino de Ciências. Realmente, depende do tipo de intervenção a que você está sujeitando os alunos. Presumivelmente, eles estariam seguindo uma instrução tradicional como tratamento controle. Então, a questão é mais em relação ao tipo de intervenção experimental à qual os alunos estarão sujeitos. Mas normalmente existem comitês de ética nas universidades e instituições de pesquisa onde tais questões são avaliadas quando se realiza pesquisa sujeita à aprovação e um comitê de pessoas determinará se a intervenção pretendida apresenta alguma consequência negativa para os alunos e esse é o melhor que podemos esperar. O que quero dizer é que não podemos erradicar experimentos da pesquisa em Ensino de Ciências, porque temos de tê-los. Mesmo que a comunidade de pesquisa não queira, políticos e políticas públicas buscam saber quais os impactos e efetividade dessas intervenções. Então, é parte da nossa cultura conduzir esse tipo de pesquisa.

RPO e DLS: A profissão de professor talvez não seja tão valorizada como a de um empreendedor ou de um administrador. Poderíamos dizer que a menor valorização seria uma razão para a pesquisa e a prática estarem tão distantes uma da outra?

S. Erduran: Penso que essa lacuna entre a pesquisa e a prática está presente ao redor do mundo. Na verdade, teríamos de buscar com afinco para achar exemplos no mundo de como essa lacuna foi preenchida eficazmente. Então, esse é um problema global.

RPO e DLS: Nós discutimos por quase meio século a ideia de que o ensino centrado em conceitos não é ideal e ainda assim encontramos formas de ensinar que consideram apenas os conceitos. Quais 
S. Erduran: Existe um pré-requisito necessário para construir a ponte, a pesquisa-ação, ou seja, professores realizando pesquisa sobre sua própria prática. Por exemplo, imagine um contexto em que os professores estão engajados em pesquisa e realizar a pesquisa também é parte da prática deles. Esse é um exemplo indicado para se pensar em como preencher essa lacuna.

Pesquisadores colaboram com professores na expectativa de diminuir essa lacuna, mas tais colaborações tendem a ser pontuais, percebe? Não são sistemáticas, não estão nos comitês, algumas funcionam, outras não. Tendem a ser ações isoladas, em vez de uma solução sistemática para lidar com a lacuna entre prática e pesquisa. Na verdade, eu penso que há muito a ser feito no sentido de criar uma infraestrutura para atacar esse problema, com pessoas alocadas nas escolas ou nas universidades dos dois lados, as quais tenham a missão de integrar a pesquisa e a prática.

Professores trabalham de acordo com algumas restrições, e pesquisadores fazem o mesmo. Quando um professor consegue realizar pesquisa-ação ou um pesquisador consegue realizar pesquisa orientada pela prática, eles estão fazendo um esforço para além do que fazem no dia a dia, pois o trabalho diário de ambos não inclui tais atribuições. As pessoas que se ocupam em diminuir essa lacuna fazem isso durante seu tempo livre, ou por interesse próprio, novamente, não uma forma sistemática de atacar o problema. Uma estratégia sistemática seria criar oportunidade para pessoas de ambas as comunidades interagirem, talvez evidenciando e reconhecendo a importância de ter pessoas dedicadas, pessoas em ambas as comunidades dedicando tempo para realizar pesquisa ou transformando pesquisas para propósitos da prática, mas isso não vai acontecer aleatoriamente. Se tivermos a infraestrutura de universidades e escolas, pessoas as quais o tempo de trabalho seja primeiramente ou predominantemente para isso, ou pessoas que sejam em algum nível dedicadas a esse problema, ao menos teríamos alguém lidando diretamente com o problema. Porque o outro aspecto seria, todos os pesquisadores precisam lidar com esse assunto? Todos os professores precisam lidar com esse assunto? Por que não podemos ser estratégicos e inteligentes com relação ao número de pessoas envolvidas com o problema de diminuir tal lacuna? Nem todos precisam lidar com isso, não todos os professores. Quero dizer, seria ótimo se tivéssemos mecanismos e espaços para tal, mas sendo realista, poderíamos começar em um local e estaríamos ao menos criando mecanismos para pessoas de ambas as comunidades serem reconhecidas por lidar com essa questão. 
RPO e DLS: Tentando fugir da falácia de que todo ensino é ruim atualmente, mas nos referindo especificamente sobre o modo de se ensinar Ciências focando apenas em conceitos, quais são as consequências desse tipo de ensino para a sociedade, considerando que um dos objetivos do Ensino de Ciências é formar cidadãos críticos?

S. Erduran: Bem, as consequências já estão presentes neste momento, pois tradicionalmente ensinamos dessa forma, então uma das consequências é que as pessoas não entendem muito o que acontece ao seu redor. Não entendem o que acontece na Ciência, não entendem quando os cientistas tratam de assuntos-chave, como mudança climática ou evolução, não entendem do que tratam esses tópicos, não entendem os conceitos envolvidos. Além disso, falta também uma compreensão sobre o processo de funcionamento da Ciência, de como a Ciência alcança seus objetivos e como os cientistas o reconhecem. Sendo assim, a consequência é um analfabetismo massivo sobre o que é a vida.

Quero dizer, na escala do indivíduo, pessoas não entendem que elas são realmente feitas de átomos, moléculas e órgãos. Não necessariamente sabem de ondem vêm (biologicamente falando), o que é bastante central na nossa existência. Se você não entende o que você é e de onde você vem, em termos de constituição genética, se você não entende tais coisas básicas, nós temos um problema. Além disso, bem, isso é só o essencial de entender a si mesmo como uma entidade biológica. Existe uma questão filosófica também, entende? Podemos buscar todos os tipos de explicações sobrenaturais para entender como chegamos e quem somos, se não conseguimos entender que somos compostos por componentes e mecanismos biológicos conhecidos.

Não apenas isso, você não está fazendo nenhum serviço para a comunidade se você não toma decisões informadas. Se você vai votar em algum político, se vai decidir qualquer coisa em contextos eleitorais, em que se vota para se decidir questões políticas para a sociedade que envolvam a Ciência em alguma instância. Então, por exemplo, você pode votar em algum político que na verdade é contra a Ciência, mas não ficou claro que ele o é, como alguns políticos são contrários à ideia de mudanças climáticas, ou que negam a existência das mudanças climáticas causadas pelo homem e você não entende quais são os argumentos desse político, você não entende o conteúdo do que está sendo tratado, você tem responsabilidade, como cidadão, como alguém consciente com o ambiente, eu espero, de causar algum bem no mundo. Então, qualquer coisa desde sua existência até sua função na sociedade intelectual, algum conhecimento sobre Ciências vai afetar a sua vida, no que você come, na sua dieta, na sua saúde. Nós usamos todos esses computadores, mas o que são computadores? O que é eletricidade? 
Quero dizer, somos consumidores de Ciência, mas a ironia é que a maior parte das pessoas que consomem Ciência não tem conhecimento sobre o que é Ciência e não o terão por decorar seus conceitos, obviamente. Os conceitos são uma dimensão de uma empreitada complexa que é a Ciência.

RPO e DLS: Sibel, gostaríamos de agradecer a você por conceder esta entrevista.

S. Erduran: Obrigada. Obrigada por trazer essas questões.

\section{REFERÊNCIAS}

AZEVEDO, Natália Helena; SCARPA, Daniela Lopes. Revisão sistemática de trabalhos sobre concepções de natureza da ciência no Ensino de Ciências. Revista Brasileira de Pesquisa em Educação em Ciências, Belo Horizonte, v. 17, n. 2, p. 579-619, 2017.

BASER, Mustafa. Fostering conceptual change by cognitive conflict instruction on students' understanding of heat and temperature concepts. Eurasia Journal of Mathematics, Science and Technology Education, London, v. 2, n. 2, p. 96-114, 2006.

BRASIL. Ministério da Educação. Base Nacional Comum Curricular. Brasília: MEC, 2017. Disponível em: <http://basenacionalcomum.mec.gov.br/\#/site/inicio>. Acesso em: 7 set. 2017.

COOK, Desmond L. The Hawthorne Effect in Educational Research. The Phi Delta Kappan, Thousand Oaks, CA, v. 44, n. 3, p. 116-122, dez. 1962. Disponível em: <http://www.jstor.org/ stable/20342865>. Acesso em: 21 out. 2014.

ELIASSON, Nina; KARLSSON, Karl Göran; SØRENSEN, Helene. The role of questions in the science classroom - how girls and boys respond to teachers' questions. International Journal of Science Education, London, v. 39, n. 4, p. 433-453, 2017. DOI: 10.1080/09500693.2017.1289420

ERDURAN, Sibel; DAGHER, Zoubeida. Reconceptualizing the Nature of Science for Science Education: scientific knowledge, practices and other family categories. Netherlands: Springer, 2014. DOI: 10.1007/978-94-017-9057-4

FREEMAN, Scott et al. Active learning increases student performance in science, engineering, and mathematics. Proceedings of the National Academy of Sciences, Washington D.C., v. 111, n. 23, p. 8410-8415, 2014. Disponível em: <www.pnas.org/cgi/doi/10.1073/pnas.1319030111>. Acesso em: 30 dez. 2015.

IRZIK, Gürol; NOLA, Robert. A Family Resemblance Approach to the Nature of Science for Science Education. Science \& Education, Cham, SW, v. 20, n. 7-8, p. 591-607, July 2011.

DOI: 10.1007/s11191-010-9293-4

KUTLUCA, Ali Yiğit; AYDIN, Abdullah. Changes in pre-service science teachers' understandings after being involved in explicit nature of science and socioscientific argumentation processes. Science and Education, Cham, SW, v. 26, n. 6, p. 637-668, 2017. DOI: 10.1007/s11191-017-9919-x

LEDERMAN, Norman. G. Students' and teachers' conceptions of the nature of science: a review of the research. Journal of Research in Science Teaching, Nova Jersey, v. 29, n. 4, p. 331-359, 1992. DOI: $10.1002 /$ tea.3660290404

LEE, Min-Hsien; WU, Ying-Tien; TSAI, Chin-Chung. Research trends in Science Education from 2003 to 2007: a content analysis of publications in selected journals. International Journal of Science Education, London, v. 31, n. 15, p. 1999-2020, 2009. DOI: 10.1080/09500690802314876

LIN, Tzu-Chiang; LIN, Tzung-Jin; TSAI, Chin-Chung. Research Trends in Science Education from 2008 to 2012: a systematic content analysis of publications in selected journals. International Journal of Science Education, London, v. 36, n. 8, p. 1346-1372, 2014.

DOI: $10.1080 / 09500693.2013 .864428$ 
MATTHEWS, Michael R. Changing the focus: from Nature of Science (NOS) to Features of Science (FOS). In: KHINE, Myint Swe (Ed.). Advances in Nature of Science Research: Concepts and Methodologies. Netherlands: Springer, 2012. p. 3-26. DOI: 10.1007/978-94-007-2457-0_1

MORTIMER, Eduardo Fleury; EL-HANI, Charbel Niño. Conceptual profiles: a theory of teaching and learning scientific concepts. Dordrecht: Springer, 2014.

NGSS LEAD STATES. Next Generation Science Standards: For States, By States. Washington, DC: The National Academies, 2013.

SCHWARTZ, Renné S.; LEDERMAN, Norman G.; CRAWFORD, Barbara A. Developing views of nature of science in an authentic context: an explicit approach to bridging the gap between nature of science and scientific inquiry. Science Education, v. 88, n. 4, p. 610-645, July 2004. DOI: $10.1002 /$ sce.10128

SERRAO, Luis Felipe Soares et al. A experiência de um indicador de letramento científico. Cadernos de Pesquisa, São Paulo, v. 46, n. 160, p. 334-361, abr./jun. 2016. Disponível em: <http://dx.doi.org/10.1590/198053143498>. Acesso em: 17 ago. 2016.

SILVA, Adjane da Costa Tourinho; MORTIMER, Eduardo Fleury. Contrastando professores de estilos diferentes: uma análise das estratégias enunciativas desenvolvidas em salas de aulas de Química. Revista Electrónica de Enseñanza de Las Ciencias, Vigo, v. 12, n. 3, p. 524-552, 2013.

TSAI, Chin-Chung; WEN, Meichun Lydia. Research and trends in science education from 1998 to 2002: a content analysis of publication in selected journals. International Journal of Science Education, London, v. 27, n. 1, p. 3-14, 2005. DOI: 10.1080/0950069042000243727 